\title{
The NSA/SHEBA Cloud \& Radiation Comparison Study
}

\author{
Janet M. Intrieri \\ NOAA/Environmental Technology Laboratory \\ Boulder, Colorado 80305 \\ Matthew D. Shupe \\ Cooperative Institute for Research in the Environmental Sciences \\ NOAA/University of Colorado \\ Boulder, Colorado 80309
}

\begin{abstract}
Cloud and radiation data from two distinctly different Arctic areas are analyzed to study the differences between coastal Alaskan and open Arctic Ocean region clouds and their respective influence on the surface radiation budget. The cloud and radiation datasets were obtained from 1) the DOE North Slope of Alaska (NSA) facility in the coastal town of Barrow, Alaska, and 2) the SHEBA field program, which was conducted from an icebreaker frozen in, and drifting with, the sea-ice for one year in the Western Arctic Ocean. Radar, lidar, radiometer, and sounding measurements from both locations were used to produce annual cycles of cloud occurrence and height, atmospheric temperature and humidity, surface longwave and shortwave broadband fluxes, surface albedo, and cloud radiative forcing. In general, both regions revealed a similar annual trend of cloud occurrence fraction with minimum values in winter (60-75\%) and maximum values during spring, summer and fall (80-90\%). However, the annual average cloud occurrence fraction for SHEBA (76\%) was lower than the 6-year average cloud occurrence at NSA (92\%). Both Arctic areas also showed similar annual cycle trends of cloud forcing with clouds warming the surface through most of the year and a period of surface cooling during the summer, when cloud shading effects overwhelm cloud greenhouse effects. The greatest difference between the two regions was observed in the magnitude of the cloud cooling effect (i.e., shortwave cloud forcing), which was significantly stronger at NSA and lasted for a longer period of time than at SHEBA. This is predominantly due to the longer and stronger melt season at NSA (i.e., albedo values that are much lower coupled with Sun angles that are somewhat higher) than the melt season observed over the ice pack at SHEBA. Longwave cloud forcing values were comparable between the two sites indicating a general similarity in cloudiness and atmospheric temperature and humidity structure between the two regions.
\end{abstract}




\section{Introduction}

The Arctic is a region that is highly sensitive to temperature change and accordingly has been postulated to show initial signs of a changing climate system (Washington and Meehl 1989). In fact, in recent years, many changes in the Arctic's natural systems have been observed in the U.S. and Canadian Arctic regions: decrease in sea-ice extent (e.g., Walsh and Chapman 2000), increase in surface temperatures (Rothrock et al. 2000), decrease in sea-ice thickness (Overpeck et al. 1997; Serreze et al. 2000), increase in UVB at the surface (Shindell et al.1998), precipitation pattern changes (Dickson et al. 2000), and the northward migration of forest, taiga, and tundra (Sturm 2003). Societal impacts have also recently become more apparent, such as coastal erosion on long-standing northern communities, permafrost heaving causing structure and road damage, and subsistence hunting alterations to name a few (e.g., The Earth is Faster Now, Krupnik and Jolly, eds. 2002). How these aforementioned changes fit into the puzzle of natural long-term variability versus anthropogenic forcing remains to be understood. One of the ways in which scientists are currently addressing the study of this changing region is by obtaining long-term records of Arctic observations and utilizing them to improve the modeling of the present and future Arctic climate.

Understanding clouds and their radiative impact in the Arctic is one of the critical steps towards unraveling model uncertainties and climate prediction. Clouds play an especially important and amplified role at high latitudes because the polar surface is characterized by high albedos and the polar atmosphere is much drier than lower latitudes. Arctic clouds also strongly influence the yearly sea-ice cycle of melting and formation (Maykut and Untersteiner 1971) so any potential feedback from clouds, in a changing climate scenario, can be substantially important. For example, changes in surface temperature, sea-ice concentration, aerosol loading, atmospheric stability, etc. will undoubtedly affect the properties of clouds, and a change in cloud properties will, in turn, affect the radiation at the sea-ice surface. However, neither this cloudradiation feedback mechanism nor is it's relation to the ice-albedo feedback, both critical components in a changing climate scenario at high latitudes, are well understood (Curry et al. 1996). It comes as no surprise then that small differences in the way clouds are represented in General Circulation Models (GCM's) can have a strong influence on $\mathrm{CO}_{2}$ climate response studies (Senior and Mitchell 1993). 
In this study, we utilize Arctic datasets from two distinctly different Arctic regions to a) create a baseline of data in a region where measurements are generally lacking, b) investigate the differences between coastal Alaskan and Arctic Ocean region clouds, and c) determine the respective influences of clouds on the surface radiation budget. The cloud and radiation datasets were obtained at the Department of Energy's (DOE) Atmospheric Radiation Measurement (ARM) North Slope of Alaska (NSA) facility in Barrow, Alaska, from 1998 to 2003, and the Surface Heat Budget of the Arctic (SHEBA) program, obtained over the Western Arctic Ocean region during 1997-1998. Similar cloud and radiation observations obtained in both locations by lidar, radar, and radiometers allow for a comparison of cloud occurrence and physical properties between these two distinctly different regions. Radar, lidar, radiometer, and sounding measurements from both locations were also used to produce annual cycles of cloud occurrence and height, atmospheric temperature and humidity, surface broadband fluxes, surface albedo, and cloud radiative forcing. This measurement comparison allows us to understand how representative the cloud and radiation observations made over land (at NSA) are of the greater Arctic Ocean region.

In this report, we present a brief review of the instruments and models used as part of this analysis in Section 2. In Section 3, we summarize results from the SHEBA data set analysis within the context of results from six years worth of data from the NSA data site. Additionally, in Section 4, we summarize the results of a journal article we have published as part of our DOE/ARM funding on the surface radiative impact of diamond dust using SHEBA data. A summary and discussion of future work are presented in Section 5.

\section{Instrument, Model and Analysis Information}

The instrumentation from the SHEBA field program and the NSA facility used as part of this study were similar with only one notable difference: the lidar at SHEBA, the Environmental Technology Laboratory's (ETL) Depolarization and Backscatter Unattended Lidar (DABUL), included depolarization ratio measurements. Depolarization ratio data provides a means for assessing the presence of liquid versus ice phase in a cloud layer. (We note that lidar depolarization measurements have recently been added at the NSA). Otherwise, the measurements were ostensibly identical and included cloud reflectivity from the Millimeter Cloud Radar (MMCR), shortwave (SW) and longwave (LW) fluxes from upward and downward 
looking broadband hemispheric radiometers, liquid water path (LWP) derived from microwave radiometer, and temperature and humidity profiles from atmospheric soundings. Although, the soundings at SHEBA and NSA provide identical information, the frequency of the soundings was much greater during SHEBA (2-4 per day/everyday) versus those obtained at NSA (once per day/weekdays-only). Cloud morphology information such as cloud base and top heights and frequency of occurrence are created from a combination of lidar, ceilometer, and radar data to provide the best possible estimate. For additional information on SHEBA instruments please refer to Intrieri et al. (2002a) and Persson et al. (2002). For additional information on the NSA site and instrument specifics refer to www.arm.gov.

Annual cycles of surface shortwave and longwave fluxes and surface cloud radiative forcing (SCF), defined as the difference between the all-sky and clear-sky net surface radiative fluxes, have already been produced for SHEBA (Intrieri et al. 2002b). Cloud forcing provides an estimate of how much a cloud changes the surface radiative fluxes relative to clear skies, and has become a common means for quantifying the radiative relationships between clouds and the radiation budget (Ramanathan et al. 1989). The LW, SW and total surface cloud forcing (SCF) are given as:

$$
\begin{aligned}
& C F L W=F(A c)-F(0) \\
& C F S W=Q(A c)-Q(0) \\
& S C F=C F L W+C F S W
\end{aligned}
$$

Where $A c$ is the cloud fraction and $F$ and $Q$ are the net surface LW and SW fluxes, respectively. Positive forcing values indicate that clouds impart a warming effect at the surface relative to clear skies (i.e., a greenhouse effect) and negative forcing values indicate that clouds impart a cooling effect relative to clear skies (i.e., the albedo effect). Cloud forcing at the surface is calculated using ground-based measurements of broadband fluxes for the all-sky values and modeled fluxes for the clear-sky values since clear skies occur so infrequently in the Arctic. In order to derive the SHEBA and NSA surface cloud forcing values, modeled clear-sky radiation results were calculated using the Santa Barbara DISORT Atmospheric Radiative Transfer code (SBDART: Richiazzi et al. 1998). The NSA fluxes and SCF's were calculated and processed in the same way as the SHEBA dataset for consistency and to minimize extraneous error. 
Measurements used for input into the SBDART model included temperature and relative humidity profiles from radiosondes and surface albedo from the SW radiometer. Interpolating atmospheric conditions between sounding times can introduce errors given that weather can change significantly and weather systems can pass through undetected in that amount of time. During SHEBA, radiosondes were launched every 6-12 hours (7 days per week) therefore, interpolating between times introduced less error than interpolating between times at NSA where soundings were only obtained once per day on weekdays. The surface albedo, a critical parameter in cloud forcing calculations, was calculated from the upward and downward looking SW radiometer hourly averaged flux values at both SHEBA and NSA. These measurements are therefore most representative of the local areas within view of the radiometers.

Standard inputs for the model included ozone and aerosol profiles. We tested two standard ozone profiles in the Arctic: a McClatchey standard profile and the default profile used in the Streamer radiation model (Key and Schweiger 1998). Although there were differences between the two, it translated to very little difference in the calculated downwelling SW fluxes and we ultimately decided to use the Streamer Summer and Winter Arctic ozone profiles for our model runs. Profiles of aerosol are not available for either SHEBA or the Barrow, Alaska region. Therefore, we ran several clear-sky model test runs to determine which compared most closely to the observed downwelling SW measurements at NSA under clear-sky conditions. In general, all model default aerosol profiles (tropospheric, rural, and marine) produced fluxes that under-estimated the amount of solar radiation reaching the surface when compared to measurements. The test run that came closest to the observations was the one where no aerosol was included; clearly an unrealistic scenario. Whether the radiometer calibrations or the clearsky model calculations or a combination of both are contributing to the offset is currently unresolved. The most reasonable solution was to tune the clear-sky model runs by a factor in order to match the downwelling solar radiation observed by the SW radiometers. This was done for each individual year and ranged between 10 and 15 percent. Continued assessment and improvement of Arctic aerosol information is needed and is currently being pursued by NOAA's Climate Monitoring and Diagnostics Laboratory (Personal Communication, John Ogren, CMDL).

\section{SHEBA and NSA Surface Cloud Forcing}




\section{a. Total Cloud Forcing Annual Cycle}

The annual cycle of total SCF (CFLW + CFSW) at SHEBA (Fig. 1, top panel - solid bold line) shows that clouds induced surface warming throughout most of the year with only a short period of surface cooling in the middle of summer, when cloud shading effects overwhelmed cloud greenhouse effects. At NSA, the annual trend is the same, (warming in winter, spring and fall), but the summer cooling effect is much stronger and lasts much longer when compared to SHEBA (Fig. 1, top panel - regular lines). The total SCF at NSA falls below $0 \mathrm{Wm}^{-2}$, dipping down to $\sim-100 \mathrm{Wm}^{-2}$, for 3 months (from early June to mid September) while at SHEBA, the total SCF only fell below $0 \mathrm{Wm}^{-2}$, dipping to $-5 \mathrm{Wm}^{-2}$, for the month of July. The seasonal averages for the total SCF at SHEBA are $30 \mathrm{Wm}^{-2}$ for fall, winter and spring and -10 $\mathrm{Wm}^{-2}$ for summer (defined as the time period when the SCF is negative). At NSA, the seasonal averages (averaged over all six years) are $37 \mathrm{Wm}^{-2}$ for fall, winter and spring and $-60 \mathrm{Wm}^{-2}$ during summer (again, defined as the time period when the SCF is negative).

The greatest year-to-year variability at NSA is noted during the summer melt season and the least amount of year-to-year variability is observed during the fall freeze-up. The yearly variability of the total SCF at NSA between the six years of data is $\sim 30 \mathrm{Wm}^{-2}$ during winter, spring and fall, however, during early summer, the variability is greater, varying by as much as $\sim 80 \mathrm{Wm}^{-2}$ between 1998 and 2002. The variability in magnitude and the timing of the total SCF is greatest during the early summer season due to fluctuations in the timing of the melt season onset and local weather-related events that produce extended periods of clear skies and fluctuations in cloud amount and precipitation (which affects albedo). By the same reasoning, the data suggest that the fall season shows a much more consistent cloud and weather pattern (as well as albedo remaining high with lowering temperatures) between each NSA year, translating to greater consistency in cloud forcing. Fig. 2 illustrates 20-day averages of cloud fraction from NSA and SHEBA. Note the more consistent values between day 250 and 320 (September through November) with cloud fractions varying only between 85 and 100\% whereas between day 150 and 250 (June through August) the fractions fluctuate between 70 and 95\%.

In general, the annual cycle of NSA total cloud forcing reveals several points: 1) cloud amounts are fairly consistent and did not change substantially in the Barrow region during the fall, winter and spring seasons over the six year analysis period, 2) late spring and summer are 
most variable since there are more late spring season weather-related disturbances that vary the onset of the melt season, and 3) cloud's in the Barrow region have fairly consistent boundaries by which they affect the surface radiation $\left(<50 \mathrm{Wm}^{-2}\right.$ in fall, winter and spring and $>-150 \mathrm{Wm}^{-2}$ in summer). In order to understand the specific differences between the two regional annual cycles, including the inter-annual melt season onset variability and smaller-scale anomalous events at NSA, it becomes necessary to break the total SCF into its component LW and SW parts as discussed below.

\section{b. Longwave Cloud Forcing Annual Cycle}

Cloud and radiation study results from SHEBA (Shupe and Intrieri 2004) showed that LW Cloud Forcing (CFLW) is a function of cloud temperature, height, and emissivity (which is a function of cloud microphysical properties). The trend and magnitude of the cloud warming effect on the surface during the entire annual cycle is fairly similar at both SHEBA and NSA, with clouds warming the surface in the LW between 10 and $70 \mathrm{Wm}^{-2}$ throughout the year (Fig. 1, middle panel). This warming is predominantly due to the fact that clouds are optically thicker (i.e. stronger emitters) than the clear atmosphere. The warming is accentuated by the frequent occurrence of temperature inversions that, at times, cause clouds to emit at temperatures warmer than the surface. In winter, surface temperatures are much warmer under cloudy skies than during clear conditions and in all seasons clouds containing small liquid water droplets are efficient emitters in the longwave, becoming essentially black at LWP's greater than $30 \mathrm{gm}^{-2}$. The average LWCF during SHEBA was $\sim 38 \mathrm{Wm}^{-2}$ while at NSA the 6-year averages were approximately $45 \mathrm{Wm}^{-2}$.

The similarity in the magnitudes of the CFLW between the two regions is due to the similar atmospheric temperature structure and cloudiness found at both locations. The differences in the LWCF are attributed to the relative amount of clouds observed between the two sites. In general, NSA had greater cloud occurrence values in all seasons except for summer than was observed at SHEBA (refer to Fig. 2). For example, in early winter at SHEBA (bold line between days 0 and 50) there were substantially less clouds present than at NSA so the forcing values are smaller. During mid-summer ( Day 200), for all years except 2003, NSA was less cloudy than SHEBA, so the LW forcing values are accordingly lower during that period at NSA. By the same logic, there is a fall season (September-November: days 240 and 310) 
CFLW maximum present in all of the measurement years which coincides with the cloudiness occurrence maximum values in both locations. In general, the CFLW response is positive and fairly flat throughout the year so, in and of itself, the longwave component does not introduce the significant amount of seasonal structure present in the Total SCF.

\section{c. Shortwave Cloud Forcing Annual Cycle}

Cloud and radiation results from SHEBA (Shupe and Intrieri 2004) showed that SW Cloud Forcing (CFSW) is a function of cloud transmittance (i.e., cloud microphysical properties), surface albedo, and the solar zenith angle. The CFSW cloud cooling effect (i.e., the SW shading effect of clouds) in summer is significantly stronger at NSA than at SHEBA (Fig. 1, bottom panel). At SHEBA, the 20-day average CFSW values dipped to $\sim-50 \mathrm{~W} \mathrm{~m}^{-2}$ in July (centered around day 190). At NSA, the 20-day average CFSW values typically ranged two to three times greater than the SHEBA values, dipping to more negative values between -100 to $150 \mathrm{~W} \mathrm{~m}^{-2}$.

This amplified shortwave radiative effect during summer at NSA is directly related to the much lower surface albedos (Fig. 3) as well as the somewhat higher insolation values and Sun angles. Generally speaking, the snow/ice surface never fully melted away at SHEBA. For practical purposes, the radiometers at SHEBA were sited on a multi-year ice floe so that the instrumentation wouldn't need to be relocated due to melting. In fact, ablation shields (plywood boards painted white) were placed around the base of the meteorological tower to ensure that the instruments would make it through the summer. In this manner, the albedos calculated at the singular radiometer point near the tower were kept artificially higher with typical albedos being 0.10-0.15 greater than the average albedos determined from a $200 \mathrm{~m}$ line (see Fig. 5, Intrieri et al. 2002b; Perovich et al. 2002).

Taking into account the lower line-averaged values at SHEBA produced lower Total Cloud Forcing values, dipping below $0 \mathrm{~W} \mathrm{~m}^{-2}$ between early June to mid-August and a minimum value of $\sim-45 \mathrm{~W} \mathrm{~m}^{-2}$ (see Fig. 11, Intrieri et al. 2002b). However, even at these lower SHEBA albedo values, the NSA SW and Total Cloud Forcing are still twice as large. The reason boils down to the fact that at NSA the snow fully melts away to reveal bare dirt and tundra. At SHEBA, the minimum albedo values were 0.50 for the point measurement and 0.38 for the lineaveraged measurement, while at NSA these values are typically $\sim 0.15$. Together, those data 
indicate that the surface albedo is the major source of CFSW difference between SHEBA and NSA.

Solar Zenith Angle (SZA) also contributes to the differences observed between the CFSW at SHEBA and NSA. The SZA determines the potential amount of solar radiation available at the surface and how long the sun is above the horizon. Since the SHEBA drift site was $1000 \mathrm{~km}$ North of Barrow, the minimum summer SZA was $54^{\circ}$ compared to a minimum SZA of $50^{\circ}$ at Barrow. Thus, at SHEBA the annual maximum insolation was about $650 \mathrm{~W} \mathrm{~m}^{-2}$, while the NSA maximum is nearly $750 \mathrm{~W} \mathrm{~m}^{-2}$. Shupe and Intrieri (2004) found that at SHEBA the SWCF was always less than 25\%, but typically around 3-10\%, of the total insolation. Therefore, a small but significant portion of the CFSW difference between SHEBA and NSA can be directly attributed to SZA.

As stated above, some of the year to year variability at the NSA site is directly related to the onset of the melt season and its impact on surface albedo. On average, the melt onset occurs around June 9 to19 (day 160-170) but was observed as early as May 27 (day 147) in 2002 and as late as June 28 (day 179) in 1999. After melt has fully occurred the variability in the observed CFSW is often due to extended periods of clear skies present over Barrow Alaska (Fig. 1, bottom panel; e.g. day 190 during 1998, 2001, 2002) when the forcing values effectively increase because forcing under clear skies is zero. In spite of the variable spring melt onset, there appears to be little variability in the timing of the fall transition back to a snow covered surface.

\section{d. Sensitivity of Cloud Forcing}

We examined the sensitivity of the cloud occurrence to the cloud forcing for both the LW and the SW Forcing values. By definition, cloud forcing under clear skies is equal to zero and under $100 \%$ overcast skies the forcing is at it's maximum. At SHEBA, we found that the sensitivity of CFSW to cloud fraction was negatively correlated and ranged between 0.0 and -1.0 $\mathrm{W} \mathrm{m}^{-2}$ per percent cloudiness (Shupe and Intrieri 2004) whereas at NSA values approached twice that to around $-2.0 \mathrm{~W} \mathrm{~m}^{-2}$ per percent cloudiness under overcast sky conditions (Figs. 4 and 5). At SHEBA, the CFLW and cloud fraction were positively correlated and the sensitivity was about $0.65 \mathrm{~W} \mathrm{~m}^{-2}$ per percent cloudiness (Fig. 4). At NSA the sensitivity is slightly higher at about $0.75 \mathrm{~W} \mathrm{~m}^{-2}$ per percent cloudiness (Fig. 5). In summary, the warming effect of clouds on the surface during winter is similar at SHEBA and NSA, mostly due to the ever-present inversion 
and similar atmospheric temperatures, while the summer shading effect of clouds at Barrow is much greater than at SHEBA because of the significantly lower surface albedos and higher insolation values.

\section{Diamond Dust Analysis}

As part of our ARM funded project, we also published a journal article on the surface radiative impact of diamond dust in Journal of Climate (Intrieri and Shupe 2004). Atmospheric observations from active remote sensors and surface observers, obtained in the Western Arctic Ocean between November 1997 and May 1998, were analyzed to determine the physical characteristics and to assess the surface radiative contribution of diamond dust (Intrieri and Shupe 2004). The observations showed that diamond dust contributed only a negligible radiative effect to the sea-ice surface. Surface radiative fluxes and radiative forcing values during diamond dust events were similar in magnitude when compared to observed clear-sky periods. Combined information from lidar, radar, and surface observers showed that diamond dust occurred $\sim 13 \%$ of the time between November and mid-May over the Arctic Ocean and was not observed between mid-May and October. Diamond dust vertical depths, derived from lidar measurements, varied between 100 and 1000 m but were most often observed to be about $250 \mathrm{~m}$.

Lidar and radar measurements were analyzed to assess if precipitation from boundary layer clouds was present during times when surface observers reported diamond dust. This analysis revealed that surface observers had incorrectly coded diamond dust events $\sim 45 \%$ of the time. The miscoded events occurred almost exclusively under conditions with limited or no illumination (December through March). In 95\% of the miscoded reports, lidar measurements revealed the presence of thin liquid water clouds precipitating ice crystals down to the surface.

\section{Summary and Recommendations}

Comparison of measurements from a coastal Alaska region and an open Artic Ocean region revealed important similarities and differences in terms of cloud forcing. In general, both regions revealed a similar annual trend of cloud occurrence fraction with minimum values in winter (60-75\%) and maximum values during spring, summer and fall (80-90\%). However, the annual average cloud occurrence fraction for SHEBA (76\%) was lower than the 6-year average cloud occurrence at NSA (92\%). Both Arctic areas also showed similar annual cycle trends of 
cloud forcing with clouds warming the surface through most of the year and a period of surface cooling during the summer, when cloud shading effects overwhelm cloud greenhouse effects. The greatest difference between the two regions was observed in the magnitude of the cloud cooling effect (i.e., shortwave cloud forcing), which was significantly stronger at NSA and lasted for a longer period of time than at SHEBA. This is predominantly due to the longer and stronger melt season at NSA (i.e., albedo values that are much lower coupled with Sun angles that are somewhat higher) than the melt season observed over the ice pack at SHEBA. Longwave cloud forcing values were comparable between the two sites indicating a general similarity in annual cloudiness and atmospheric temperature and humidity structure between the two regions. Given the substantial shortwave radiation differences however, caution should be taken when extrapolating the NSA regional cloud and radiation results to the greater Alaskan Arctic Ocean sector.

Several issues relating to NSA measurements surfaced during the course of this analysis. Quite simply, increasing the Sounding Frequency and providing baseline, seasonal Profiles of Ozone and Aerosol Models would improve the accuracy for the clear sky model results and thus reduce the error in the cloud forcing values. Additionally, understanding the occurrence and radiative impact of Diamond Dust Studies at NSA would be highly useful not only for comparison with the open Arctic Ocean region statistics already documented but to provide additional surface radiation budget information during winter and spring at NSA. Case Studies of pivotal events are recommended, such as the melt onset and the fall freezes, to provide information on the variability and weather scenarios that affect critical their timing. It is our goal and hope that this study will serve as a baseline of cloud forcing information and continue to be built upon as a long-term cloud and radiation climate dataset. Continuing the data record both forward in time using NSA measurements, as well as, back in time potentially using CMDL radiation data would prove extremely useful in trying to understand how Arctic climate is evolving in the Barrow sector.

\section{Related Publications}

\section{a. 2004 Publications directly under ARM Project Funding}


Intrieri, J.M. and M.D. Shupe, 2004: Characteristics and Radiative Effects of Diamond Dust over the Western Arctic Ocean region. Journal of Climate, 17, 2953-2960.

Shupe, M.D., and J.M. Intrieri, 2004: Arctic surface cloud forcing at SHEBA, Part 1: The impact of cloud properties, surface albedo, and solar zenith angle. Journal of Climate, 17, 616628.

Intrieri, J.M., and M.D. Shupe, 2004: Arctic cloud forcing determined by lidar cloud measurements and broadband surface radiometers. International Laser Radar Conf., 12-16 July, 2004, Matera, Italy, ESA SP-561, 573-576.

\section{b. 2003-2004 Publications related to Arctic Cloud Research}

Morrison, H., M. D. Shupe, and J.A. Curry, 2003: Modeling clouds observed at SHEBA using a bulk microphysics parameterization implemented into a single-column model. J. Geophys. Res., 108(D8), 4255, doi:10.1029/2002JD002229.

Morrison, H., J. A. Curry, M. D. Shupe, and P. Zuidema, 2004: A new double-moment microphysics parameterization, Part 2: Application to Arctic stratiform clouds. J. Atmos. Sci., accepted.

Zuidema, P., B. Baker, Y. Han, J. Intrieri, J. Key, P. Lawson, S. Matrosov, M. Shupe, R. Stone, and T. Uttal, 2003: The characterization and radiative impact of a springtime mixed-phase cloud boundary layer observed during SHEBA. J. Atmos. Sci., accepted.

Matrosov, S.Y., M.D. Shupe, A.J. Heymsfield, and P. Zuidema, Radar estimations of ice optical properties, Proceedings of the 13th Annual ARM Science Team Meeting, Broomfield, CO, March 31 - April 3, 2003.

Zuidema, P., B.B. Baker, J.M. Intrieri, P. Lawson, S.Y. Matrosov, M.D. Shupe, and T. Uttal, Studies of Arctic mixed-phase clouds with high liquid water paths from SHEBA/FIRE/ACE, Proceedings of the 13th Annual ARM Science Team Meeting, Broomfield, CO, March 31 - April 3, 2003.

Zuidema, P., B.B. Baker, J.M. Intrieri, P. Lawson, S.Y. Matrosov, and M.D. Shupe, Studies of Arctic mixed-phase clouds from SHEBA/FIRE/ACE: May 1-10 case study, Proc. $7^{\text {th }}$ Conf. on Polar Met. and Ocean., AMS, 12-16 May, Hyannis, MA, 2003.

Morrison, H., M.D. Shupe, J.A. Curry, and P. Zuidema, Modeling a multi-layer cloud system observed during the FIRE Arctic Clouds Experiment using a new double-moment bulk microphysics scheme, Proc. $7^{\text {th }}$ Conf. on Polar Met. and Ocean., AMS, 12-16 May, Hyannis, MA, 2003. 


\section{References}

Dong, X., and G. G. Mace, 2003: Arctic stratus cloud properties and radiative forcing derived from ground-based data collected at Barrow, Alaska. J. Climate, 16, 445-461.

Intrieri, J.M., and M. D. Shupe, 2004: Characteristics and radiative effects of diamond dust over the Western Arctic Ocean region. J. Climate, 17, 2953-2960.

-----, M. D. Shupe, B. J. McCarty, T. Uttal, 2002a: Arctic cloud statistics from lidar and radar at SHEBA. J. Geophys. Res., 107, 8030, doi: 10.1029/2000JC000423.

-----, C. F. Fairall, O. G. P. Persson, M. D. Shupe, and R. M. Moritz, 2002b: Annual cycle of cloud forcing over the Arctic. J. Geophys. Res., 107, 8039, doi:10.1029/2000JC000439.

Key, J. and A.J. Schweiger, 1998: Tools for atmospheric radiative transfer: Streamer and Fluxnet. Computers \& Geosciences, 25, 443-451.

Krupnik, I., and D. Jolly, (eds.) 2002: The Earth is Faster Now: Indigenous Observations of Arctic Environmental Change. Fairbanks, Alaska: Arctic Research Consortium of the United States. 384 pp., ISBN 0-9720449-0-6.

Perovich, D.K., T.C. Grenfell, B. Light, and P.V. Hobbs, 2002: Seasonal evolution of the albedo of multiyear Arctic sea-ice. J. Geophys. Res., 107, doi:10.1029/2000JC000438.

Persson, P. O. G., C. W. Fairall, E. L Andreas, P. Guest, and D. Perovich, 2002: Measurements near the Atmospheric Surface Flux Group tower at SHEBA: Near-surface conditions and surface energy budget. J. Geophys. Res., 107, 8045, doi:10.1029/2000JC000705.

Ramanathan V., et al., 1989: Climate and the Earth’s radiation budget. Physics Today, 22-32.

Ricchiazzi, P., S. Yang, C. Gautier, and D. Sowle, 1998: SBDART: A research and teaching software tool for plane-parallel radiative transfer in the Earth's atmosphere. Bull. Am. Meteor. Soc., 79, 2101-2114.

Shupe, M. D., and J. M. Intrieri, 2004: Cloud radiative forcing of the Arctic Surface: The influence of cloud properties, surface albedo, and solar zenith angle. J. Climate, 17, 616-628.

Washington, W. M., and G. A. Meehl, 1989: Climate sensitivity due to increased $\mathrm{CO}_{2}$ : Experiments with a coupled atmosphere and ocean general circulation model, Clim. Dyn., 4, 138. 


\section{Figure Captions}

Fig. 1. Annual cycle of 20-day average of total surface cloud forcing (top), longwave surface cloud forcing (middle), and shortwave surface cloud forcing (bottom) for SHEBA (solid bold line) plus six years of NSA data. All values in $\mathrm{Wm}^{-2}$.

Fig. 2. 20-day averages of cloud fraction for SHEBA (solid line) and six years of data from NSA.

Fig. 3. Annual cycles of albedo for six years of NSA plus SHEBA (dashed line, top panel).

Fig. 4. Scatter plot of CFLW (top) and CFSW (bottom) versus cloud fraction amount for SHEBA.

Fig. 5. Scatter plot of CFLW (top) and CFSW (bottom) versus cloud fraction amount for NSA. 


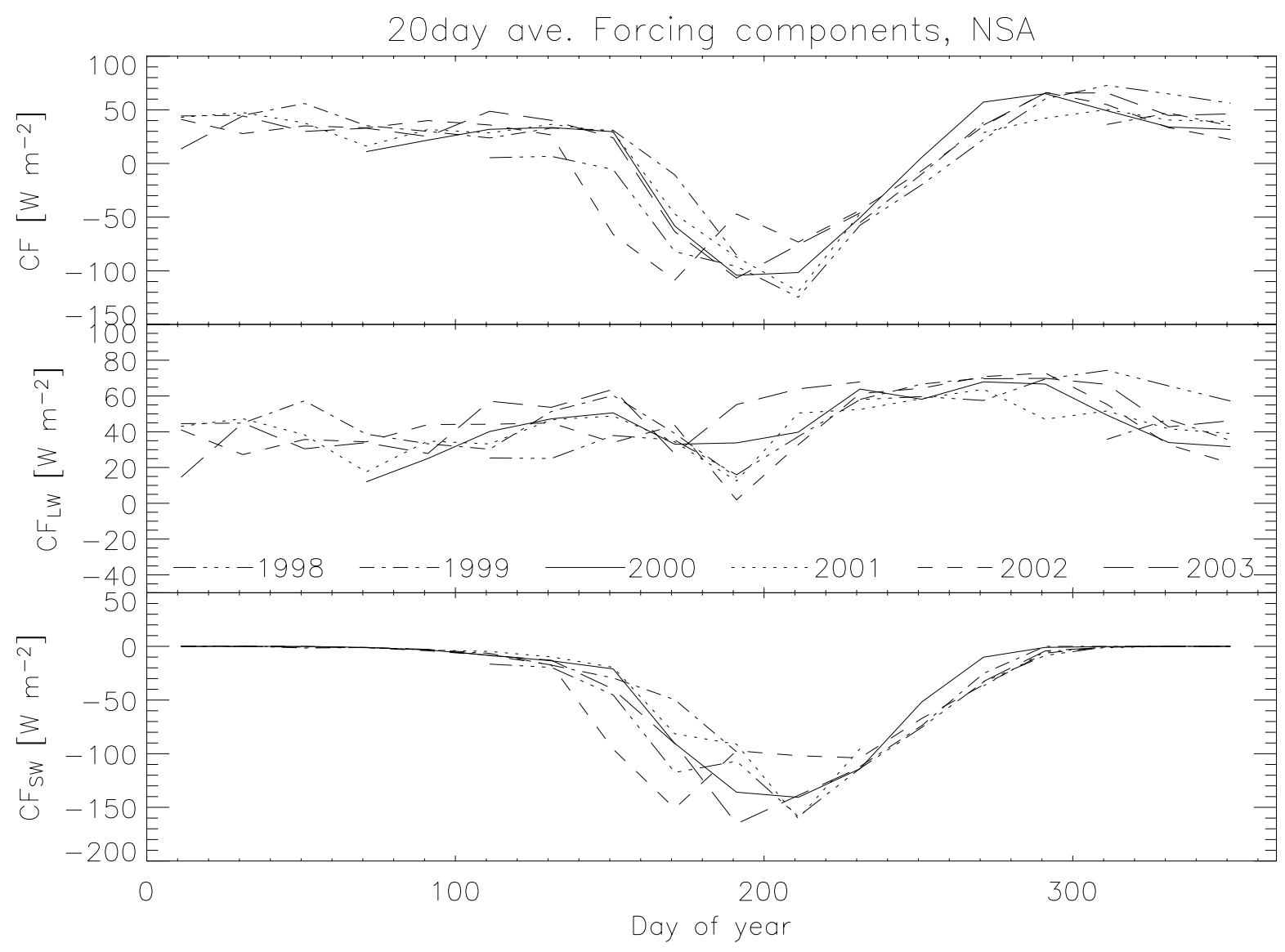

Fig. 1 


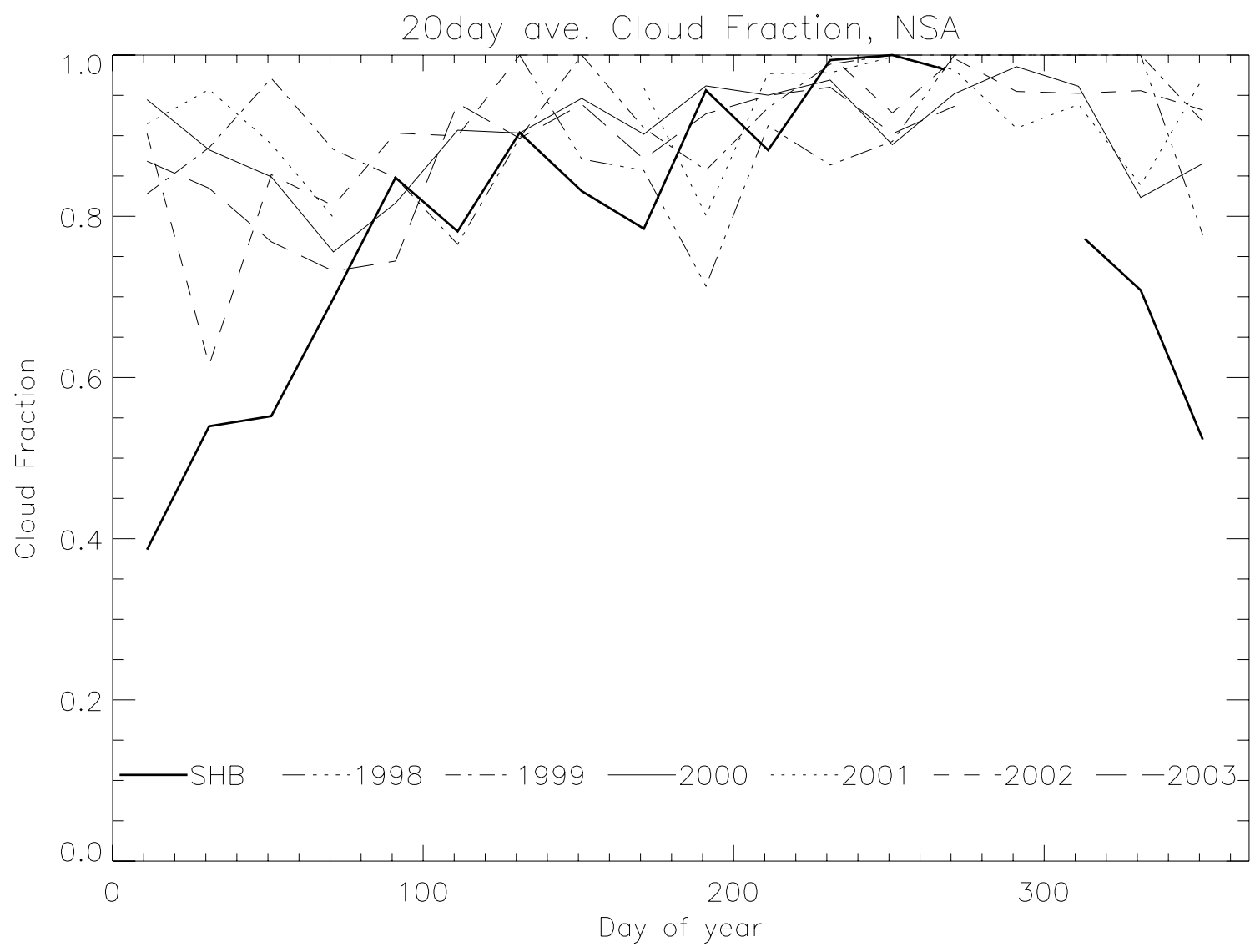

Fig. 2 


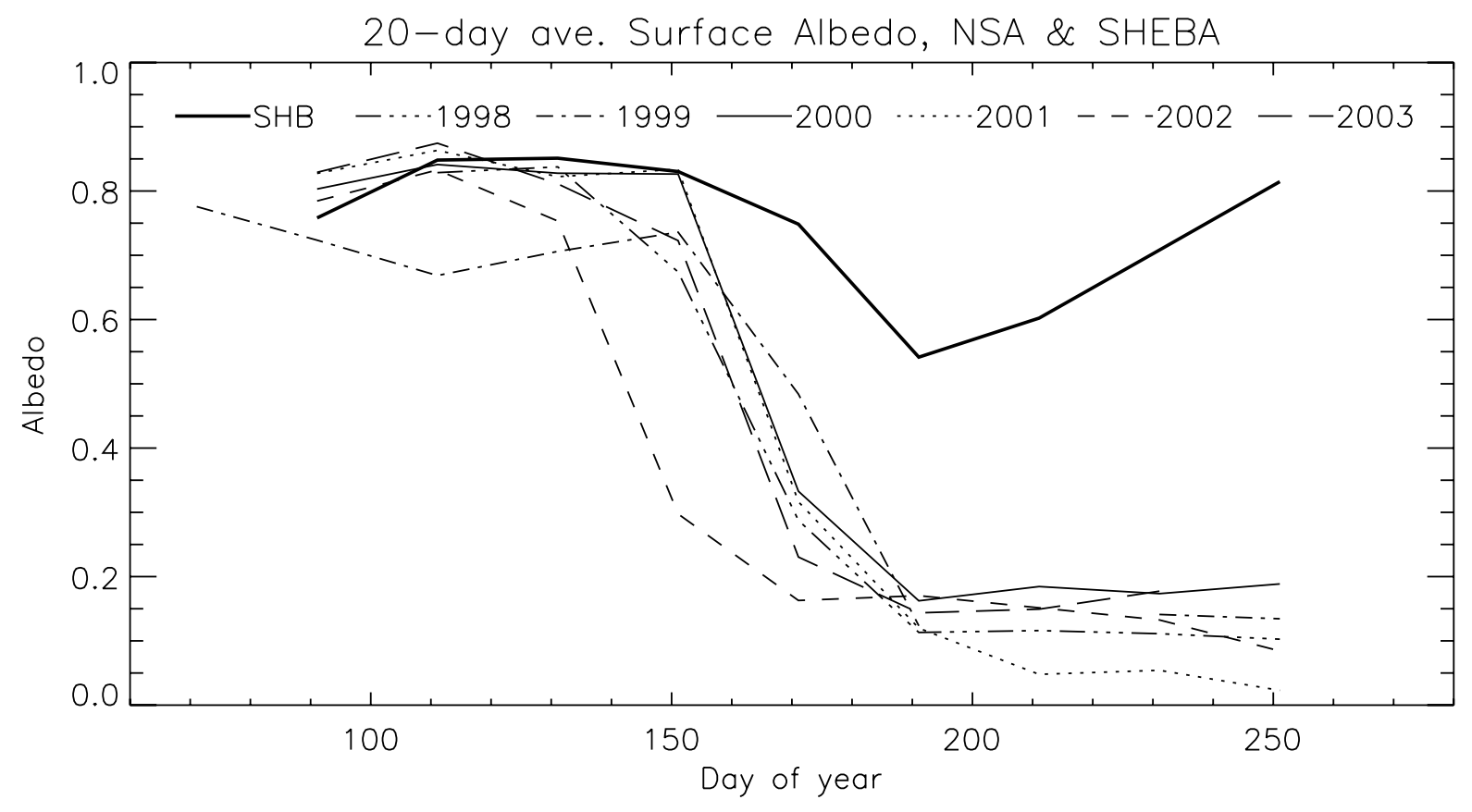

Fig. 3 

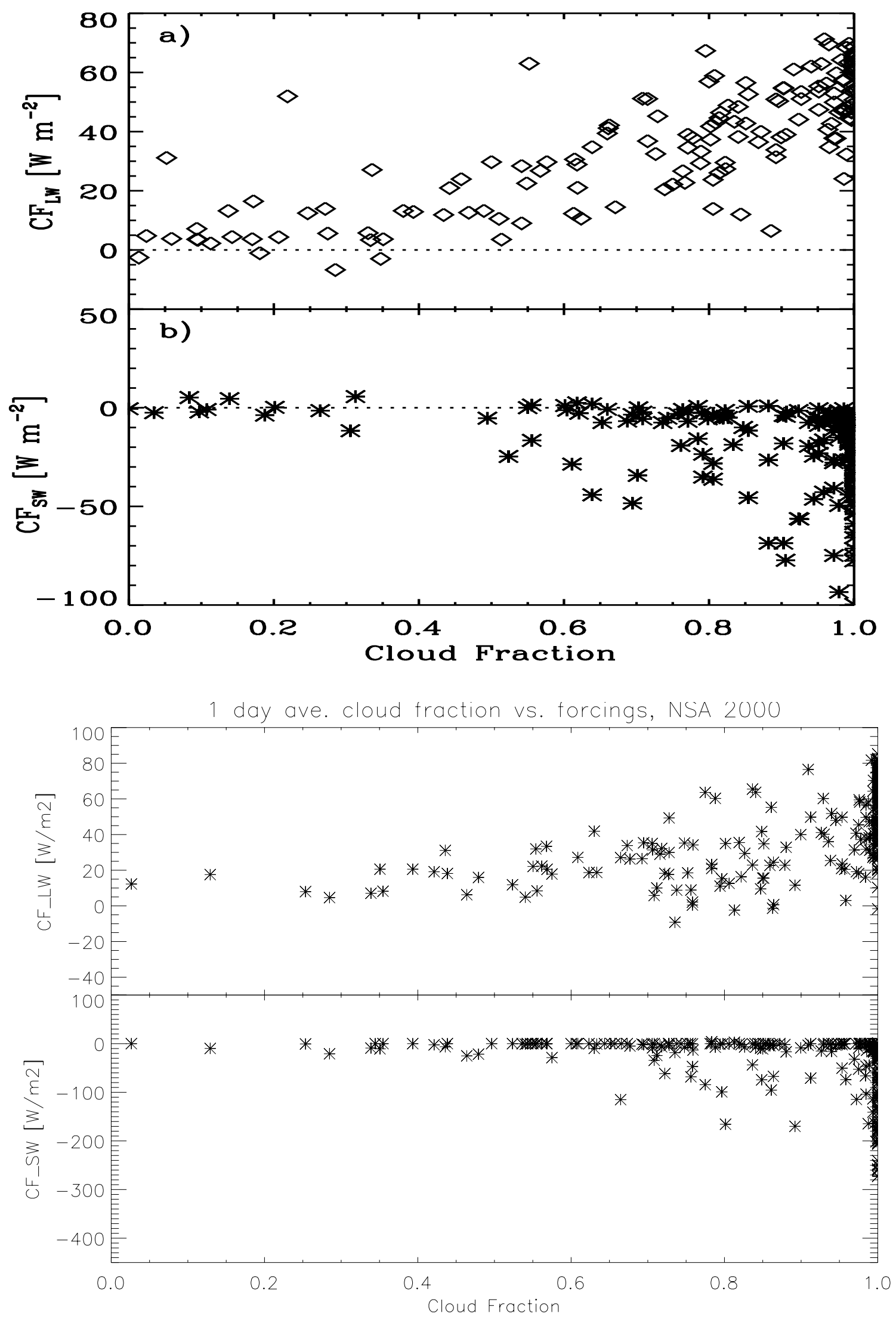

Figs. 4 and 5 